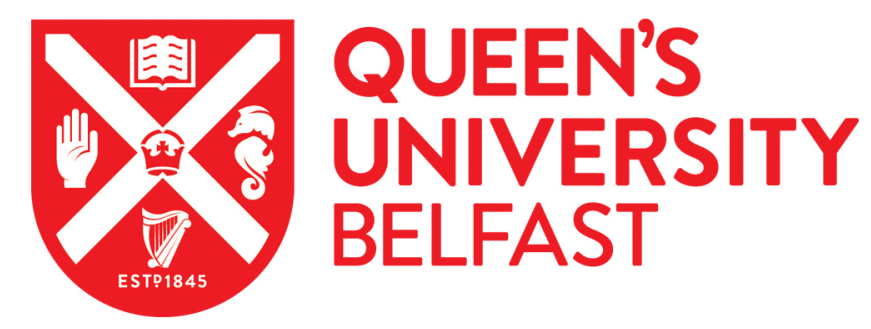

\title{
Hearing the voices of kinship foster carers in Northern Ireland: An inquiry into characteristics, needs and experiences
}

Houston, S., Hayes, D., \& MacDonald, M. (2018). Hearing the voices of kinship foster carers in Northern Ireland: An inquiry into characteristics, needs and experiences. Families, Relationships and Societies, 7(2), 227-247. https://doi.org/10.1332/204674316X14676449115315

Published in:

Families, Relationships and Societies

Document Version:

Peer reviewed version

Queen's University Belfast - Research Portal:

Link to publication record in Queen's University Belfast Research Portal

Publisher rights

(C) 2016 Ingenta.

This is a post-peer-review, pre-copy edited version of an article published in Families, Relationships and Societies. The definitive publisherauthenticated version [insert complete citation information here] is available online at: [insert URL here]" - See more at: http://policypress.co.uk/self-archiving\#sthash.DtX9mENr.dpuf

\section{General rights}

Copyright for the publications made accessible via the Queen's University Belfast Research Portal is retained by the author(s) and / or other copyright owners and it is a condition of accessing these publications that users recognise and abide by the legal requirements associated with these rights.

Take down policy

The Research Portal is Queen's institutional repository that provides access to Queen's research output. Every effort has been made to ensure that content in the Research Portal does not infringe any person's rights, or applicable UK laws. If you discover content in the Research Portal that you believe breaches copyright or violates any law, please contact openaccess@qub.ac.uk. 


\section{Hearing the Voice of the Kinship Foster Carer in Northern Ireland:}

\section{An Inquiry into Characteristics, Needs and Experience}

This study describes an investigation into the characteristics, needs and experiences of kinship foster carers in Northern Ireland. A number of salient themes were captured by adopting a mixed-methods approach with 54 carers. It was found that the respondents were predominantly grandparents who experienced a significant incidence of health-related issues. The cohort also endured high levels of stress, particularly at the beginning stage of the placement. Consequently, their need for practical, emotional and respite support was most evident. In terms of the children for whom they cared, many required help at school, and some presented with challenging emotions and behaviours. Overall, these findings emphasised the importance of relationship-based social work and demonstration of accurate empathy to the carer.

\section{Introduction}

Over the last five years in Northern Ireland, there has been a significant increase in the number of kinship, foster carers. These carers look after children who are biologically related to them, or with whom they have a significant attachment. Kinship foster carers are assessed and approved by their local, statutory Health and Social Care Trust, and the children are either the subject of a Care Order or voluntarily accommodated in care. Such placements are made in response to a range of parental difficulties including mental illness, substance misuse or bereavement. The central legislative instrument, the Children (Northern Ireland) Order 1995, and the regional policy for children in care, Care Matters: A Bridge to a Better Future (2007), indicate that children should be placed with a family member or close friend, provided this move is in their best interests. It is recognised that placements with relatives can preserve the child's link with their biological parents.

Yet, there is a consensus in the international research (see below) that kinship carers face unique challenges that complicate their caring role. Regarding the population in Northern Ireland, the last study of these challenges was completed by Lernihan in 2003 . Since then, there have been notable demographic, institutional and legislative changes affecting carers and care provision in the region including new ways of delivering services. There is a pressing requirement, therefore, to carry out an up-to-date review of these carers' needs. Such 
information is needed to drive the development of responsive, person-centred services for this population (O'Brien, 2012).

\section{Reviewing the Needs of Kinship Carers}

The following review of the literature explores what is known about the particular needs of this group of carers. Centrally, it appears that grandparents form the largest proportion of kinship carers in the UK. Many studies, focusing on this group, highlight the prevalence of illhealth or disability in this population, as well as the social challenges that accompany the resumption of a parenting role that is anomalous with their age-related peers. Put another way, this cohort reported more limitations on their daily activities, and poorer emotional and physical health, compared with grandparents freed of these responsibilities (Cuddeback, 2004).

Some studies have concentrated on kinship care provided by a sibling of one of the birth parents (Selwyn and Nandy, 2012). Their needs appear to be somewhat different to those of grandparent carers (Nandy et al, 2011). Selwyn and Nandy (2012) found that the former were more likely to be materially impoverished. Also, most were single females in their early 30s, and already caring for young children in overcrowded households. Given their lone parent status, and extensive caring responsibilities, these sister-carers were either unemployed or part-time workers. This might partly explain Farmer's (2010) finding that placements with grandparent carers were less likely to experience disruption compared with care provided by other relatives.

Significantly, many kinship foster carers experience stress as a result of their caring role. For example, in McSherry et al's (2013) Northern Ireland based study, targeting a sample of 30 kinships carers, a third felt strain and pressure. This is not only a regional idiosyncrasy but is also reflected in international research. From their comparison of kin and non-kin foster carers in Spain, for instance, Palacios and Jimenez (2009) found that the former experienced higher levels of stress compared with the latter. Thus, $85 \%$ of their sample of 56 highly stressed carers fell into the kinship category compared with only $15 \%$ of non-kinship carers.

The various stressors encountered by kinship foster carers are summarised adroitly by Coakley et al (2007, p.99) as: 
'issues of attachment and loss, dealing with the emotional, behavioural, or physical problems of foster children, dealing with "the system", adjusting to fostering, concern that the child will go back to living in a bad situation, and dealing with the birth family'.

Many of these issues are shared in common by all foster carers. For example, kinship and non-kinship foster carers alike are caring for children who have more behavioural and educational difficulties compared with children in the general population (Cuddeback, 2004). To reiterate, though, there is evidence (O'Brien, 2012) that kinship carers face additional demands arising from their impecuniosity, unfamiliarity with social work systems, and complex family relationships. Generally speaking, they are more likely to be unemployed, have subordinate educational attainments, and are located in lower socio-economic social classes than non-kinship foster carers (Cuddeback, 2004).

Moreover, since many kinship placements arise due to a family crisis, carers may not have adequate time, nor the financial and practical resources, to prepare for the imposed changes (Coakley et al, 2007; Palacios and Jimenez, 2009). Moreover, the sense of being ill-prepared, can accentuate stress in the early stages of the placement (Denby, 2011b). Typically, many kinship foster carers will have had no previous contact with social workers (Palacios and Jimenez, 2009) and are consequently ill-equipped to apprehend the intricacies of agency policy, or navigate labyrinthine, bureaucratic systems and structures.

Kinship placements are seen as viable settings for establishing contact between children and their birth parents (Cuddeback, 2004). However, intra-familial relationships in these contexts can be troubled, labile, estranged and emotionally embroiled (Lernihan \& Kelly, 2006; Vanschoonlandt et al, 2012 ). Even though birth parents and their relative carers may share a similar culture and psycho-biographical background, we cannot assume that these common attributes lead to better co-operation between them. $\underline{\text { Hence, in a comparison of } 142 \text { kinship }}$ and 128 non-kinship placements, Farmer (2010) reported that 54\% of the former experienced difficult relationships with the child's parents, compared to $16 \%$ of the latter. Importantly, a kinship placement becomes more tenuous when there are strained relationships between these actors (Coakley et al, 2007). 
Despite such challenges, kinship carers invariably demonstrate high levels of commitment to the child (Farmer, 2010). This sense of fidelity may be a factor explaining why kinship placements are, in general, more stable, compared to their non-kinship counterparts (Cuddeback, 2004). Another reason may be that many children tend to experience comparative stability before entering the kinship arrangement. Farmer's (2010) comparison of the two types of placement provides further insight into the factors promoting such stability. She found that being formally approved as a kinship carer, and the associated financial and practical support that followed, was linked with lower levels of placement disruption. However, as in non-kinship placements, the likelihood of disarrangement increased significantly the older the child when first placed.

For some kinship carers, another source of stress arose from ill-defined legal rights and responsibilities. In their study of Northern Irish kinship carers, Lernihan and Kelly (2006) found that $17 \%$ (out of a sample of 107) of kinship carers, compared to $13 \%$ (out of a sample of 121) of non-kinship carers, had secured a Residence Order (a disposal instituted by the Court directing a child's living arrangements). Moreover, in the absence of a statutory directive, that would elucidate parental responsibility, kinship carers felt insecure particularly regarding decisions affecting the child's life. Nonetheless, even when a Residence Order had been granted, some carers worried about the possible reaction of birth parents to a change in the child's legal status (Lernihan and Kelly, 2006).

To conclude, despite the findings from this body of research, we do not have a clear, up-todate picture of the characteristics, needs and experiences of kinship carers in Northern Ireland. The next section outlines how the study was designed to address this gap in knowledge.

\section{Method}

The aim of the research was to ascertain the characteristics, needs and experiences of kinship foster carers in Northern Ireland. More specifically, it sought to:

- acquire a demographic profile of the carers addressing their psycho-social and economic characteristics; 
- ascertain the carers' perceptions of the characteristics and needs of the children to whom care was afforded;

- describe the circumstances of the placement and processes of assessment, approval and maintenance;

- develop a greater understanding of the needs of the carers; and

- explore the caregivers' experiences with social services, in order to identify unmet needs and good practice.

Two forms of data collection were utilised, namely: (a) a questionnaire and (b) a follow-up, in-depth, semi-structured interview. A questionnaire was chosen as it was appropriate for carrying out a survey of the needs of this particular population. In terms of the target group, a systematic random sample was taken from the list of all kinship foster carers who were members of The Fostering Network (Northern Ireland): a regional charity promoting the rights and needs of foster carers. (All foster carers in Northern Ireland, including approved kinship foster carers, were members of this Network). This led to 80 carers being identified out of a total population of 450 carers. 54 carers (68\%) subsequently agreed to take part in this first stage of data acquisition and their characteristics are set out below in the findings section of this article. At the outset, these carers were reassured by the Fostering Network that their participation was purely voluntary, confidential and subject to their informed consent; and that choosing not to take part, would not affect any services offered to them.

The questionnaire was administered by a Fostering Network Development Worker through a face-to-face meeting with the primary carer in her home. Aside from this atypical datacollection task, the Development Worker's main role was to offer informal support to the carers and advocate for them. Prior to these interviews, they had been briefed by managers in the Fostering Network, in conjunction with the researchers, to ensure standardisation and continuity in approach when applying the instrument. Moreover, the questionnaire had been previously piloted (with other carers who were not part of the sample) and amended to make sure it was coherent and relevant.

The questionnaire covered areas such as the carers' personal and social characteristics; the nature of their living arrangements, home circumstances and finances; details of the children fostered; the circumstances surrounding the placement and the process of assessment; the 
carers' view of contact with social services; and the carers' support needs. In terms of data analysis, the results were entered into an SSPS software package. Descriptive statistics for each item were extracted and cross-tabulations analysed. Lastly, adopting an iterative approach, the researchers read and re-read the qualitative comments recorded on the questionnaires in response to open questions. The aim was to familiarise ourselves with essential meanings within this data. Following this step, core patterns were identified by comparing and contrasting textual items. A representative set of quotations, capturing these patterns, were then selected to support the written presentation of the findings.

Using a purposive sampling approach, a sub-cohort (who had completed the questionnaire, and were willing to engage further in the process) were subsequently invited to participate in a follow-up, semi-structured interview. Here, the focus was on identifying a mixed sample in terms of the respondents' personal and social characteristics. A further criterion was 'best fit' with the study's aim and objectives. In other words, the researchers were keen to identify a sample of primary carers who could provide in-depth information about their needs and experiences. The selection process resulted in nine kinship foster carers being identified for the interview. Of the group, nine were grandparents including two single carers; the rest were Uncle and Aunt care-takers. The children were mostly adolescents falling in an age range of 10 to 17 years. Notably, the children's birth parents were living elsewhere but had contact with them.

The interview explored a range of areas including how the placement came about; the needs of the child and carers; the nature of the support provided and any gaps in that support; the factors that helped and hindered the placement; the level of participation with Social Services in planning and decision-making processes; and the carers' perceptions of the future. The interviews were carried out with the carers in their own homes by universitybased researchers who did not have any prior knowledge of, or relationship, with them.

A phenomenological approach was adopted in the interviews. This placed an emphasis on the essential meaning of the carer's experience. Hence, the approach was idiographic; that is, it aimed to probe and unravel memories, reflections and narratives. The respondents were encouraged, therefore, to recall freely what had happened to them. So, the 
questioning style was designed to encourage rich, 'thick', and vivid descriptions of experience.

Later on, the content of the interviews was transcribed and subjected to a thematic analysis (Howitt and Crammer, 2014). Thus, once the data was recorded, it was subsequently read and re-read a number of times. The objective was to achieve familiarisation with the data so that codes and themes could then be discerned. The codes represented a preliminary level of abstraction away from the verbatim data. Additional analysis (of the data and codes) led to the identification of themes. As the analytical process developed, the fit between the data, the codes and themes was checked and re-checked to ensure a correspondence between all three categories.

The researchers attempted to make the study reliable by adopting method triangulation, respondent feedback, piloting the questionnaire, and by carrying out a systematic and rigorous approach to data acquisition and analysis. It was further strengthened by the researchers adopting a bracketing technique which is common in phenomenological interviews. This is where any pre-conceived views about the respondents' experience are literally 'put to one side' (as much as is possible) in order to reach the quintessential meaning of the account. That said, there were some limitations in the research design. Chiefly, the researchers did not interview the children living in the families sampled. Thus, it would have been useful to triangulate their views alongside those of their carers'. Secondly, the perspectives of the social workers were not elicited. Such views may have provided a more insightful understanding of the barriers impinging on them, and put the carers' critical comments concerning their practice within a wider context.

The study achieved ethical approval through the Fostering Network's and University's Research Ethics Committees.

\section{Results}

Results from the Questionnaire

The results arising from the questionnaire provide, firstly, some demographic information about the carers' age, relationship with the child, and the children's ages. The second section presents results relating to the carers' income and finances. It also includes data relating to 
their economic activity. The third section builds on these practical details by identifying the carers' experiences of social services and the fourth section deals with their range of support needs. The last section focuses on a set of cross-tabulations using the carer's 'age' as the foundational, comparator characteristic.

\section{Key Carer and Child Demographics}

Most of the respondents surveyed $(80 \%, n=43)$ had been carers for over 24 months. Figure 1 , below, shows the age breakdown of the cohort. $59 \%(n=32)$ of the carers were over the age of 50 and $82 \%(n=44)$ were beyond the age of 40 . The largest group were carers in their 50 s, representing a third of the total sample $(n=18) .22 \%(n=12)$ were in their 40 s and $24 \%$ $(n=13)$ in their 60s.

\section{FIGURE 1 HERE}

Figure 2, below, indicates that over half $(56 \%, n=30)$ of the sample were grandparents and, of these, $48 \%(n=26)$ grandmothers. In terms of gender breakdown, $89 \%(n=48)$ of the primary carers were female. Figure 2 shows the majority of these women were grandmothers and a significant number, aunts $(31.5 \%, n=17)$. So, these two categories accounted for $80 \%$ of the respondents.

\section{FIGURE 2 HERE}

The survey also gathered information about the age of the children being fostered. Table 1 below indicates that children of different ages were living in these familial arrangements although, in this sample, the majority $(61 \%, n=50)$ were in the post-primary, school age group. The largest group ( $26 \%$ of the sample, $n=21$ ) were aged between fourteen and sixteen. Table 1 shows that the 54 respondents in this survey collectively fostered a total of 82 children.

\section{TABLE 1 HERE}

2. Income and finances 
Respondents were asked to indicate their net, household, weekly income. The questionnaire stipulated that the fostering allowance paid in respect of the child or children was to be included in the estimation. Figure 3, below, shows the respondents' self-reported net weekly income and financial position.

\section{FIGURE 3 HERE}

All of the survey respondents were in receipt of fostering allowances from Social Services and $74 \%(n=40)$ stated this amount was adequate to meet the needs of the children. Several of those who stated it was not adequate thought that the general cost of living had increased whereas the allowance had not. Another stated that the amount a teenage boy eats' meant that the allowance was not adequate and a different respondent commented that she did not know anyone who would child mind for $£ 20$ a day.

\section{FIGURE 4 HERE}

Figure 3 shows that just under $15 \%(n=8)$ of respondents reported that their weekly net income was less than $£ 200$ and, in Figure 4, over one third $(37 \%, n=20)$ described their financial position as either 'a bit of a struggle at times' or 'challenging'. Most respondents described their income as 'manageable' $(39 \%, n=21)$ and almost a quarter described it as 'comfortable' $(24 \%, n=13)$. While respondents were likely to interpret these terms subjectively, those who added a further comment $(n=13)$ indicated concerns about future financial hardship.

The respondents were then asked to describe their employment status. Figure 5, below, shows the responses to this question. $42 \%(n=22)$ of carers who answered this question described their employment status as 'unemployed', $27 \%(n=14)$ described it as 'retired', 4\% $(n=2)$ described their status as being 'long term sickness/disability', $10 \%(n=5)$ stated they worked 'part-time' and 15\% $(n=8)$ stated they worked full time. One person described their employment status as 'homemaker'.

The lack of economic activity was striking in the sample and, when the responses were grouped into two categories of 'economically active' and 'economically inactive', $78 \%$ of 
carers who responded to this question $(n=52)$ fell in to the economically inactive category with just under a quarter (22\%) viewing themselves as economically active.

\section{FIGURE 5 HERE}

\section{Experiences of Social Services}

Figure 6, below, sets out the respondents' evaluation of their contact with social services. As can be seen, only $10 \%(n=5)$ viewed the experience as unhelpful. Just over half reported their experience of social services to have been helpful and the remainder considered it to have been satisfactory.

\section{FIGURE 6 HERE}

Some illustrative comments, from different carers, are listed below.

'We have felt very supported by the Social Services and received very wise advice'.

'Sometimes find relationship with field Social Worker difficult. Social Worker can be negative when things are positive. (I feel) I have to be 'on guard' when the Social Worker asks questions.'

'The Social Worker has a very big impact on the placement. We have experienced good and bad.'

'(Social Workers) need to listen to carers more regarding decisions affecting children.'

'I would like to be able to communicate with just one person. Not having to tell everything to lots of different people.'

\section{Support Needs}

The data indicated that educational support for children and carers was a priority area. $31 \%$ $(n=29)$ of those who responded referred to the need for educational support and $15 \%(n=14)$ mentioned support for special educational needs, meaning that, overall, $46 \%$ of carers viewed the educational domain as a crucial area requiring assistance. $12 \%(n=9)$ mentioned counselling as a support need for both the foster child and for other family members. $8 \%$ $(n=8)$ mentioned support in relation to the foster child's mental health as a need and $12 \%$ $(n=9)$ mentioned this as a need for other members of the family. 
Respondents also commented on the question: 'Is there anything else you would like to tell us about your support needs or your experience of being a foster carer?' The following comments from three different carers were representative of general sentiments:

\footnotetext{
'Independent advice/support would have been useful particularly at the beginning, for example, being given information as to what you are entitled to instead of feeling like you are 'begging.'
}

'It is very frightening at the beginning when you know you are on your own.'

'I generally get on with fostering and don't ask for things. I only find out if I am entitled to something if someone tells me.'

Several respondents indicated that managing contact with birth parents and other siblings could be problematic:

\footnotetext{
'I manage the contact with Dad and Social Worker arranges it with Mum. Dealing with parents and other family members is still the most difficult thing.'
}

'Contact with child's Mum has always been a problem and remains so.'

\section{Cross-tabulations with the Carer's Age}

A significant finding from the survey was the respondents' age profile (most being in the older category) and the fact that a majority $(56 \%, n=30)$ of carers were grandparents. Almost $60 \%(n=32)$ were over 50 and $82 \%(n=44)$ over 40 . This finding was investigated further by cross tabulating age with a range of other variables. This section focuses on disability, illness and economic issues and how these relate to the age of the carers sampled. All disability or illness was self-reported by the carer.

$15 \%(n=8)$ of the entire sample stated they suffered from a disability which affected their day-to-day life and the same percentage stated that they suffered from a long term illness which impacted on their day-to-day life. When disability/illness was cross-tabulated with age, it was noted that carers who reported having a disability were over 50 years old. Table 2 below shows the percentage of each age group who reported having disability and/or illness. 
Table 2 shows that $22 \%(n=4)$ of carers in their fifties and $31 \%(n=4)$ of carers in their sixties stated that they suffered from a disability which adversely affected their day-to-day life. $11 \%$ $(n=2)$ of the carers in their fifties, and $31 \%(n=4)$ of carers in their sixties, reported suffering from a long-term illness which adversely affected their day-to-day life. Given this data, one might have anticipated that carers in their seventies would have reported even higher levels of illness and disability, although this trend could not be verified with this sample.

Table 3, below, shows 'age' cross-tabulated with 'self-described financial position'. Two thirds of carers in their $40 s(n=8)$ described their financial position as a bit of a struggle at times. A slightly higher percentage of younger carers viewed it as challenging compared to other age groups; and the data suggests that older carers may feel somewhat more comfortable financially than their younger comparators, despite the fact that they are more likely to be economically inactive.

\section{TABLE 3 HERE}

\section{Results from the Semi-Structured Interviews}

In this section, the processes of becoming a kinship foster carer are firstly detailed. Talking about these areas often generated discussion about relationships with Social Services and how they might be improved. This theme is outlined in the second section. Thirdly, the support needs of the child/children are considered. Lastly, the final section summarises the reflective comments made by carers about their whole experience as well as their perspectives about the future. This section also reflected on what carers said helped to sustain the placement.

\section{Theme 1 - 'Everything changed from then': Becoming a kinship carer}

The comments of five of the nine respondents indicated that the placement of the child or children was made in an emergency. Although the carers had previously recognised there were problems regarding the children's care, their removal from their parents (usually mothers) was often unexpected. One carer received a telephone call from the police in the 
middle of the night. Another carer was at work when a social worker rang her and said that the children needed to be looked after immediately. In this case, the children were left in the care of the family's babysitter until the kinship carer returned from work that day. Two carers said:

'Social workers just landed in and left them... everything changed from then, with the kids, the family, with everything.'

'Two policemen called at my house out of the blue with the kids in the car.'

The carers reflected on the dilemma associated with having to make a quick decision about caring for the child:

'We didn't choose this. It was thrust upon us.'

'If you're a foster carer, you've chosen to do that. Kinship carers have no choice... It happens quickly. You don't get to train for it, it just happens.'

The carers spoke of how they felt obligated to care for their 'kin'. One carer had refused to receive the child into her home; however, her husband insisted they should because the child would 'end up in prison' if they declined. Another carer stated:

'I grew up in care so I couldn't let them grow up in care.'

Given that the kinship care arrangement was often agreed as a temporary measure, in addition to the variety of complicated issues at play within families, the process of stabilising the placement was different for each child. Several carers reported delays in the processes of being assessed and being granted care of the child:

'It took us so long to be approved because we slipped through the net... social workers were off sick.'

Evidently, the initial stage of becoming a kinship carer, could be deeply unsettling, and tantamount to a crisis in some situations. For many, the lack of choice in the matter fuelled a sense of ambivalence about taking on additional caring responsibilities. Even so, a deep filial 
obligation superseded many misgivings about the placement. In short, the blood relation imposed a duty to care. From the data, it was not always clear that social services and other agencies fully appreciated these conflictual emotional states, particularly in relation to how a crisis manifested itself in a carer's life. Hence, these findings present as a salutary reminder to professionals to view this initial stage as a significant disruption or watershed (for carers). They need to understand the heightened emotions pertaining to this phase, show empathy for the carers, and support them to effectively manage changes in role, relationship and responsibility.

\section{Theme 2 - Support needs}

Two clear support needs emerged as being important at the beginning stages of placements: practical, financial help and information support. One family spoke of how two additional children joined their own three children in December. This placement was made in an emergency during a holiday period. The children, then aged six and almost two, arrived with no coats and nothing other than the clothes they had on that day and the carers talked about not being provided with sufficient finances or equipment to meet the children's basic needs:

\footnotetext{
'I mean, that first Christmas, we had no money to give them a Christmas. But we had to...'We had never begged in our lives...It was awful...I had to borrow off my Dad.. I was so ashamed...I mean, $\mathrm{f30}$ didn't even cover (name of child's) nappies.'
}

The lack of an initial support package added stress to what was already a very challenging situation. It was suggested that carers should be given a sum of money in advance which could help meet immediate costs. For most, this included items such as a bed, wardrobe and clothes for the child coming into their care. Several carers reported relying on the charity of friends, neighbours and other family members to meet these essential and urgent needs:

'Friends gave us a bed... they arrived with clothes and shoes for him. The help from Social Services wasn't there when we needed it, it came later.' 
Lack of information about finance, in particular, was mentioned repeatedly. Carers reported not knowing about allowances and not being aware that they were able to claim for items such as mileage:

'Like, I drove to (name of place) and sat in a car park for two and a half hours. It would have been nice to know that I could have come home and the fuel would have been paid for.'

One carer also reported being given incorrect advice about benefits by a social worker, which ultimately meant that the child in their care did not receive an entitled allowance. It was when they sought outside guidance that they realised they could make a claim for the benefit.

Theme 3 - 'It's hard to trust people now': Relationships with Social Services

One of the respondents spoke about their experiences with Social Services in an entirely, positive manner. In addition, this carer spoke of how the child in her care was receiving support from a psychologist and how that psychologist was also available to provide her with beneficial support and advice including offering psychological explanations for challenging behaviour:

I now realise it all comes down to attachment issues... this really helps me to understand her behaviour.'

Positive remarks were also made about the link, supervising social worker:

'My link [supervising] social worker comes once a month and advises me on training that would be helpful...or simply talks over the issues...all these ideas are very helpful.'

The other eight respondents reflected that their experiences of social workers had been mixed. An important concern, here, was the ubiquitous changes in staffing. One carer said they had seven different social workers in the first fifteen months of the placement:

'The link [supervising] social workers were off on lots of sick leave. We had seven social workers at the beginning ... that is... the first 15 months...one we couldn't communicate with as he did not have good English. We were falling apart but he said "you are fine". It was awful.' 
Another expressed continuing frustration at having to tell and re-tell the painful history of how the child came to be in his care and his particular behavioural needs. He also relayed that the child had thirteen different social workers taking him to birth-parent contact meetings in one year. This was a child who was, at the time, suffering from night tremors and was diagnosed as being on the autistic spectrum, having an attachment disorder and ADHD:

'It was a terrible year.'

Yet, a different carer reflected more positively about her experience with her social worker:

'Our current link worker [supervising social worker] is great and gives emotional support. She comes out whenever you need her. She reinforces expectations to (name of child fostered) about his behaviour and lays down the law. He doesn't listen to her though....but we can still contact the link worker at any time.'

Carers reflected on the range of their relationships with social workers. Comments such as the following were typical of how carers viewed these relationships:

'The middle social worker was good....the kids had four and they were all good apart from one.' 'We just feel like they don't give a damn about us.'

' $X$ 's social worker comes once a month. She's more than helpful'.

'Our current link social worker is great and gives emotional support. She comes out whenever you need her... we can call her any time'.

Quite often, carers referred to social workers being absent for various reasons. One mentioned that her social worker had been off sick for six months and that no one had replaced her. Another carer surmised that, because her relationship had begun so badly with a previous social worker, it was hard to trust the new one, even though she was more efficient. That said, many of the carers showed empathy for the social workers with whom they had contact. Comments were made about the pressures of their work and their changing job roles. 
A central motif, in all of this, was the primacy of the 'relationship' between the carer and social worker: the need for trust, the belief that help was there if required, the importance of recognising the contribution carers were making, and the use of 'soft skills' such as empathy, and listening. When relationships were distant, missing or overly bureaucratic, then carers felt isolated and sometimes embittered. Social support built on the perception that one was cared for, that the right assistance was attainable, and that one was part of an understanding network. In all of this, while personal relationships with individual social workers could be empowering, experiences with the agency (as a sphere of more removed decision-making) were invariably more negatively charged. This raises the issue of how agencies recognise carers' rights, roles and contributions in policy, procedure and case management systems.

Theme 4 - 'Education is a big, big one'

All the interviewed carers, apart from one, talked about the educational needs of the child in their care and the high prevalence of these needs. For some, this was highlighted as part of the reason for the child coming into care in the first instance. Moreover, children within the sample were seen as having problems relating to autism, anger management, mental health and a range of other behaviours. All of this meant school life could be challenging. One carer paid for additional tutoring and found this had been a positive move whilst another carer mentioned receiving this from The Fostering Network and found this to be very useful. One carer evocatively said:

\footnotetext{
'Education is a big, big one... Our experience with the school has been shocking...we felt we needed to remove ' $X$ ' from the school... this was the last straw. We then saw another principal of a school and we cried in his office. We were so overcome by his compassion. He agreed to take ' $X$ '. Then an amazing change occurred. ' $X$ ' blossomed'.
}

It is unsurprising that educational issues were manifestly to the fore in these placements. Many of the children exhibited a range of educational difficulties such as poor school attendance, school exclusion, low academic achievement and expectations. These challenges could be caused by familial disruption or changes in school. Furthermore, they may also have been present in the children's lives prior to entering kinship care - even precipitating the entry to care. For the carers, therefore, it was vital that teachers were able 
to 'tune in' to these children's needs, putting their educational performance, emotional and behavioural responses within a psycho-social context, so that sensitivity could be shown.

Theme 5 - 'We decided we weren't giving up': Reflection on the overall experience In addition to information and financial support, carers mentioned that their needs for respite support were not being met. None of the carers interviewed had current respite arrangements in place. Having to have family members vetted before they could look after the child was a cause of annoyance for one family. The carers in this situation interpreted this requirement as an indication that they were not being trusted to decide who could spend time with the children. As a result, this couple stated that they no longer had time to socialise together as a couple:

'Before we maybe got out once a month and now it's maybe twice a year. They can't trust our judgement after four years of having the kids... I don't mind sitting in, but you know it would be nice to be able to maybe get out for a meal, for a walk.'

Another carer spoke of his need for respite and how it had been delayed due to checks being carried out on his chosen respite carer (his daughter). He had asked the social worker if he could leave the (cared for child) off early at his daughter's home one morning as he had an early appointment to attend. The social worker said this could not be approved. However, when asked where the child would go in an emergency, the social worker opined that he would be placed immediately with this daughter. In recounting this story, the kinship foster carer reflected:

'So, it's okay if it meets their needs, but not mine? I've had no respite and I'm not happy with it one bit.'

Carers were also asked to comment generally on their experience of being a kinship foster carer, hopes and fears for the future, and what helped or hindered the sustainability of the placement. This led to detailed descriptions of how the journey of becoming and remaining a kinship foster carer had been very challenging. Inevitably, carers were sustained by a strong will, determination and an obligation to stand by their child and their comments focussed on the emotional connections between themselves, the child, and other family members. In all of this, contact with birth parents could be strained and challenging. Yet, carers clearly indicated that their sustained efforts were rewarded by seeing the child develop and achieve 
desired milestones. Several reflected on how things had improved and 'settled' with time. The following quote from a carer, who had cared for the child in some form since he was five years old (a period now of some thirteen years), was typical of this sentiment:

'You watch a wee child come in to your home who is terrified, tired, cold and hungry. To watch him grow up in to the lovely young man he is. He is kind, he is caring. He is just lovely and we are so, so proud of him.'

Yet, in some cases the future brought manifold fears:

'We are worried this will go on forever. We have financial worries. You don't know what is round the corner. Will he (referring to a grandchild) be able to get a job?'

Another carer reflected:

We need someone... respite to engage with (mentions child's name)...someone younger than us...I am so exhausted. We have no back up in a crisis.

In terms of reflecting on the total experience and providing advice to other relatives considering taking on the role, one carer remarked:

\footnotetext{
'My main message is this: kinship carers need more advice about their entitlements from social services at the start. We could not have predicted we were to become kinship carers... it came out of the blue. Such a shock for both of us. The first statutory reviews were nightmares... Social Services should have prepared us for court. The first social worker didn't have much idea about this. We weren't told what an at-risk register was.
}

\section{Discussion and Conclusion}

This study set out to investigate the needs and experiences of kinship carers in Northern Ireland. In terms of their age profile, and relationship to the child, the participants were similar to those in other studies of kinship foster care. However, the finding that only 2 of the 54 kinship carers were siblings of the fostered child was somewhat in contrast to recent estimates of the high proportion of adult siblings thought to be providing care (Nandy et al, 2011). It would be useful to explore further the factors that influence choices about which relatives become their kinship carer. The experiences of sibling carers, especially adult 
sisters, who Nandy et al (2011) found to be the poorest kinship carers, warrant further attention as their voice is not strongly represented in this sample, and their needs may differ significantly from those of grandparents who have been the subject of more comprehensive research (Nandy et al, 2011; Selwyn and Nandy, 2012).

Again consistent with previous research (Cuddeback, 2004), the majority of kinship carers in the sample were aged 50 years and over, and a significant number of them reported either a disability or long-term illness affecting their daily life. Pointedly, these carers were mostly looking after adolescents. So, in effect, many custodians were invariably having to care for young people undergoing, not only the 'storm and stress' of adolescent development, but also loss and change. The disjuncture between the challenges of these potentially jarring, life-stage positions could be stark and was a salutary reminder of the importance of lifecourse theory (Gubrium and Holstein, 2000) for understanding the unfolding, and sometimes clashing, intersections of time, sequence, context and meaning.

Consistent with the reviews of earlier research (Cuddeback, 2004), the participants were caring for children with significant emotional and behavioural difficulties. In addition, they required a high level of support regarding the child's education. Tellingly, the likelihood of placement disruption, and breakdown of kinship care, has been found to increase significantly the older the child (at the time of placement) and if he or she had been excluded from school (Farmer, 2010). It is therefore vital that particular emphasis is placed on supporting kinship foster carers who are looking after older children, or children who have behavioural and/or emotional difficulties, and that carers are assisted to manage any educational difficulties that the child or young person may be experiencing.

In all of this, the timing of financial support appeared to be of critical importance to carers. They indicated that placements were often made in an emergency. Yet, in keeping with other sources (see O'Brien, 2012), many felt that the financial and practical supports they received at the beginning of these emergency placements were inadequate, and that professional responses were often tardy. Again, the significance of time, place and event suggests that models of crisis-intervention (Payne, 2014), along with life-course theory, may be apposite conceptual tools to promote accurate empathy and sensitive interventions. 
The study also underscored the relevance of theories of family support (Cutrona, 2005; Houston and Dolan, 2008) which indicate that interventions should be practical, emotional, respite-oriented, and provide appropriate advice. Essentially, new carers may benefit from peer contact as a form of support. Consideration could be given to finding ways of quickly linking new carers with more experienced ones, a recommendation put forward by Denby (2011a). The benefits of such peer-support networks are well documented in the literature (Aziz et al., 2012; Lin, 2014). Yet, such innovations as these may need to be buttressed by discrete recognitional practices. Thus, according to Kirton et al (2007, p. 8), a significant minority of foster carers in their UK study indicated that 'they did not feel valued or listened to despite rating their support as good or very good'. Support in itself is not enough: foster carers have legitimate claims for greater recognition. Perceptions of how they are viewed, what status is accorded to them, and how they are remunerated, are critical recognition markers.

Building on this theme, several of the survey respondents, and all of those interviewed, reported that managing contact with birth parents was challenging and emotionally stressful because of the complex family relationships involved. This echoed the findings of previous research where tensions in relationships with birth parents were more common in kinship care arrangements compared to non-kinship placements (Coakley et al., 2007; Farmer, 2010; McSherry et al., 2013). The respondents in this study were not explicit about their support needs in relation to contact arrangements but found this to be a difficult and upsetting issue to discuss. Nonetheless, contact was an area in which support was required.

By way of conclusion, and to reiterate, it was clear that having a caring, responsive relationship with a social worker was very important to the carer. In some cases, carers complained that frequent changes of social worker (both fostering support workers and children's social workers) impaired relational trust. It was clear that carers wanted continuity in their relationships with social workers, and contact with individuals who were approachable, and diligent. Thus, a foremost finding was that relationship-based, compassion-focused social work (Ruch, 2010) was valued highly by the cohort. This approach is characterised by the application of empathy, listening, perspective-taking, containing anxiety, re-framing, encouraging hope and simply 'being there' in times of need. 
This study was commissioned by the Health and Social Care Board (Northern Ireland) and carried out by the Fostering Network and Queen's University Belfast. 


\section{References}

Aziz, R, Roth, D, Lindley, B, 2012, Understanding family and friends care: The largest UK survey, London: Family Rights Group

Coakley, T, Cuddeback, G, Buehler, C, Cox, M, 2007, Kinship foster parents' perceptions of factors that promote or inhibit successful fostering, Children and Youth Services Review, 29, 92-109

Cuddeback, G, 2004, Kinship family foster care: A methodological and substantive synthesis of research, Children and Youth Services Review, 26, 623-639

Department of Health, Social Services and Public Safety, 2012 Minimum kinship care standards, Belfast: DHSSPS

Denby, R, 2011a, Kinship liaisons: A peer-to-peer approach to supporting kinship carers. Children and Youth Services Review, 33, 217-225

Denby, R, 2011b, Predicting permanency intentions among kinship caregivers, Child and Adolescent Social Work, 28, 113-131

Farmer, E, 2010, What factors relate to good placement outcomes in kinship care? British Journal of Social Work, 40, 426-444

Gubrium, J, Holstein, J, 2000, Constructing the life-course, New York: General Hall

Kinsey, D, Schlosser, A, 2013, Interventions in foster and kinship care: A systematic review, Clinical Child Psychology and Psychiatry, 18, 429-463

Kirton, D, Beecham, D, Ogilvie, K, 2007, Still the poor relations? Perspectives on valuing and listening to carers, Adoption and Fostering, 31, 6-17

Lernihan, U, 2003, A study of kinships care in relation to selected characteristics and attitudes to social services involvement, PhD Thesis, Queen's University Belfast

Lernihan, U, Kelly, G, 2006, Kinship care as a route to permanent placement, In Iwaniec, D, ed, The child's journey through care: Placement stability, care planning and achieving permanency, London: John Wiley and Sons

Lin, C, 2014, Evaluating services for kinship care families: A systematic review, Children and Youth Services Review, 36, 32-43

McSherry, D, Fargas Malet, M, Weatherall, K, 2013, Comparing long-term placements for young children in care: The care pathways and outcomes study Northern Ireland, London: BAAF

Nandy, S, Selwyn, J, Farmer, E, Vaisey, P, 2011, Spotlight on kinship care, Bristol: University of Bristol

O'Brien, V, 2012, The benefits and challenges of kinship care, Child Care in Practice, 18, 127146 
Vanschoonlandt, F, Vanderfaeillie, J, Van Holen, F, DeMaeyer, S, Andries, C, 2012, Kinship and non-kinship foster care: Differences in contact with parents and foster child's mental health problems, Children and Youth Services Review, 34, 1533-1539

Palacios, J, Jimenez, J, 2009, Kinship foster care: Protection or risk? Adoption and Fostering, 33, 64-93

Selwyn, J, Nandy, S, 2012, Sibling kinship carers in England: Evidence from the 2001 UK population census, Children and Youth Services Review, 24, 194-199 
Figure 1: Age of carers

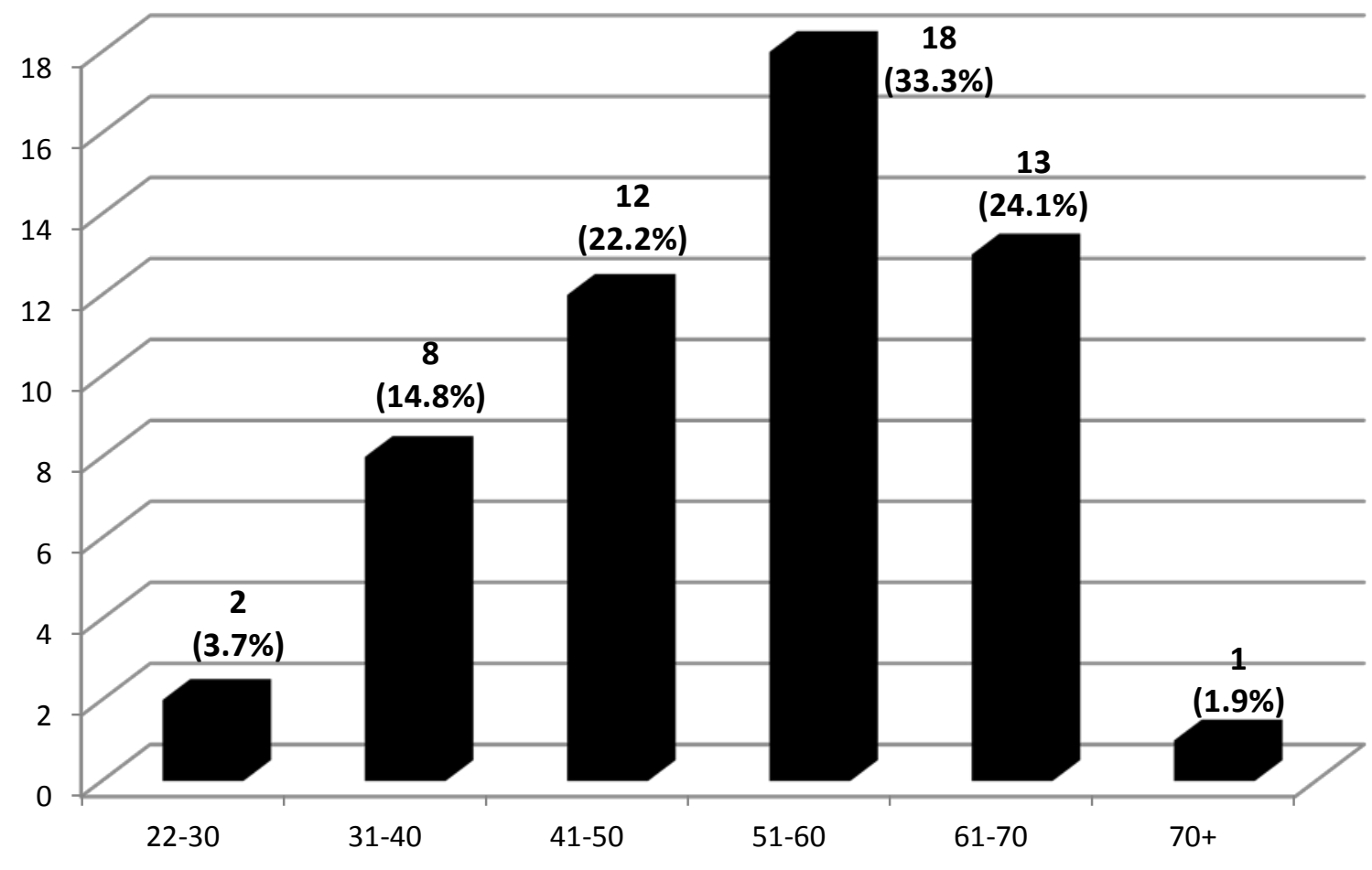

Figure 2: Primary carer's kinship relationship to child

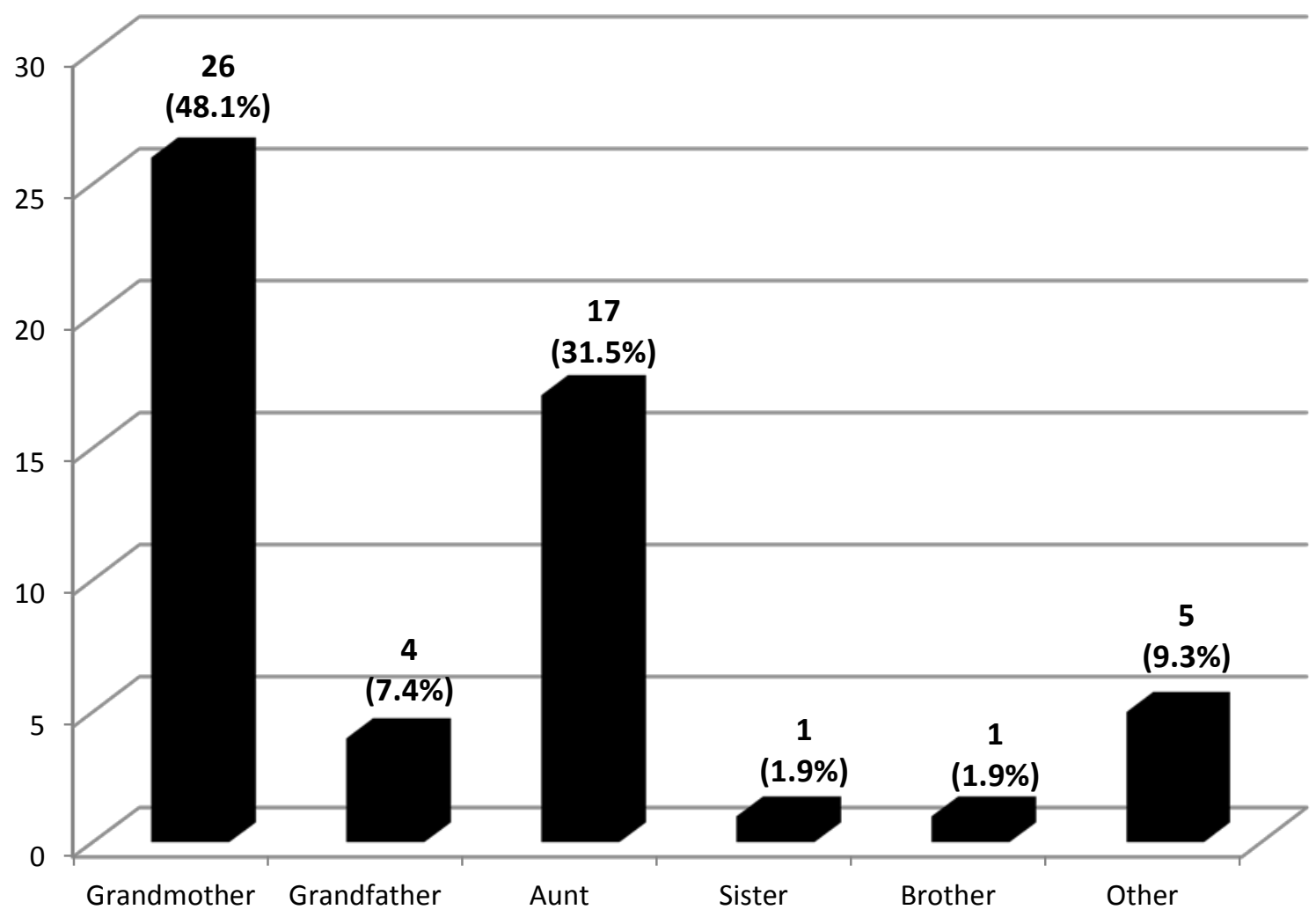


Figure 3: Self-described total net household weekly income

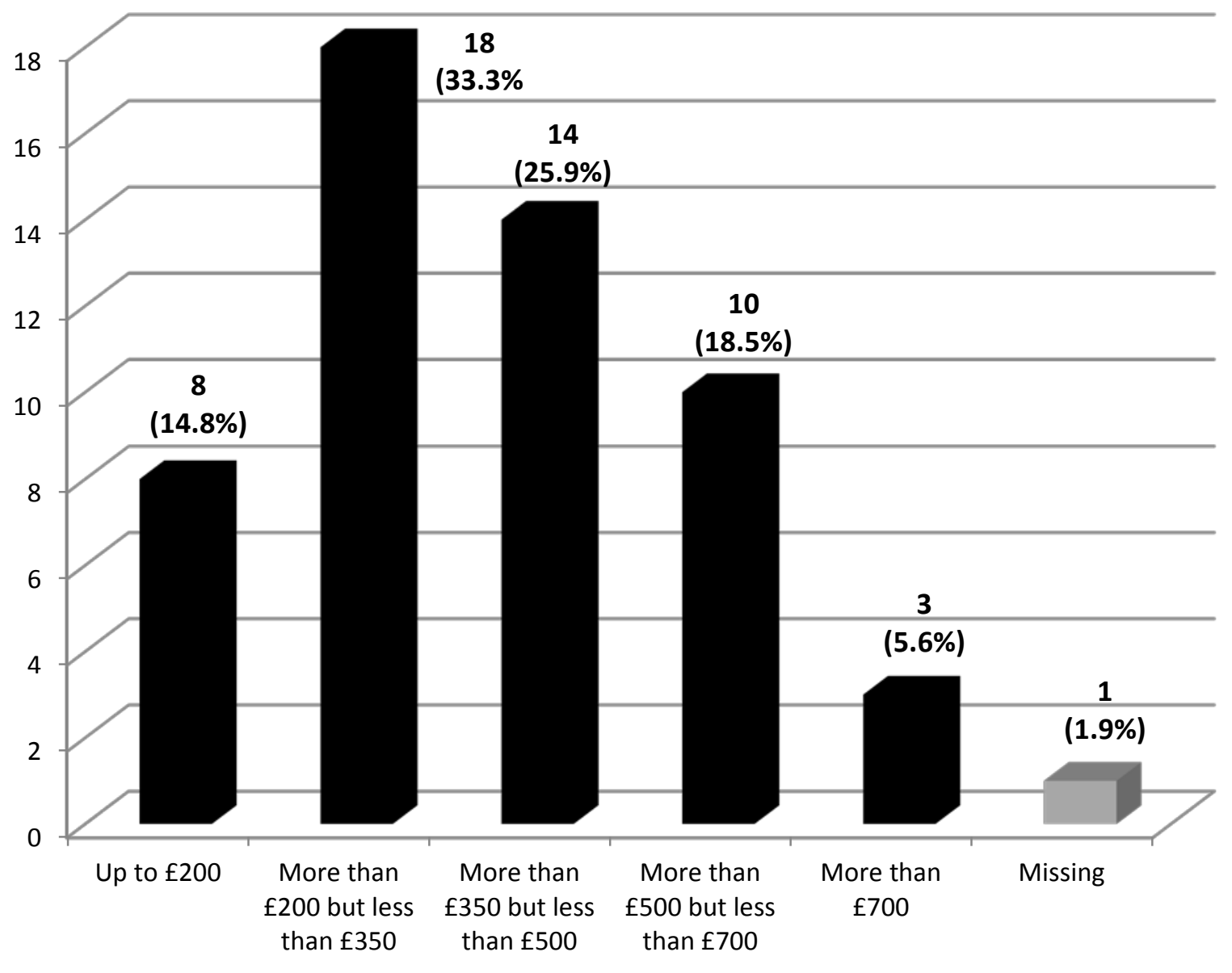


Figure 4: Self-described financial position

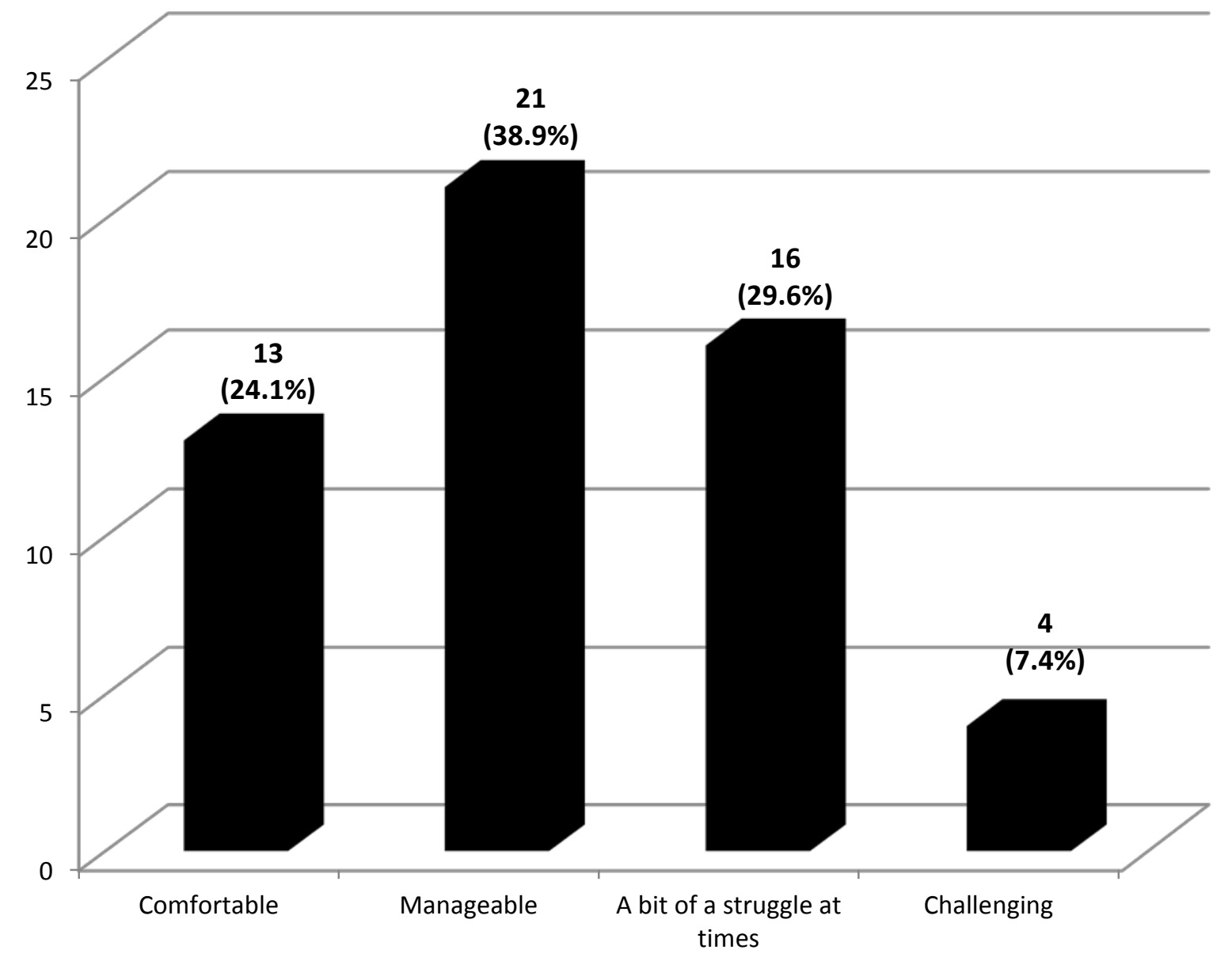


Figure 5: Employment status of kinship foster carer

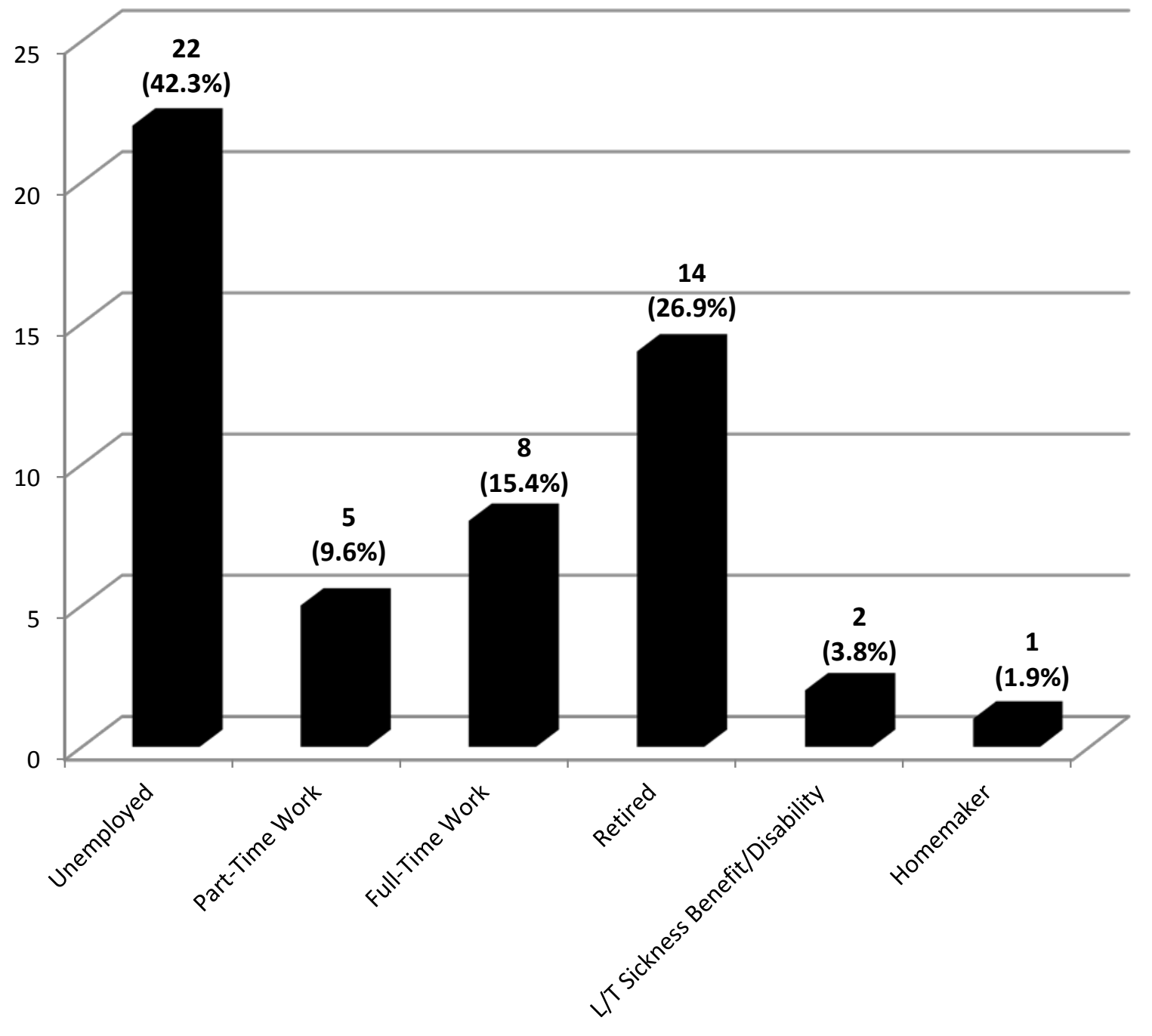


Figure 6: Experiences with Social Services

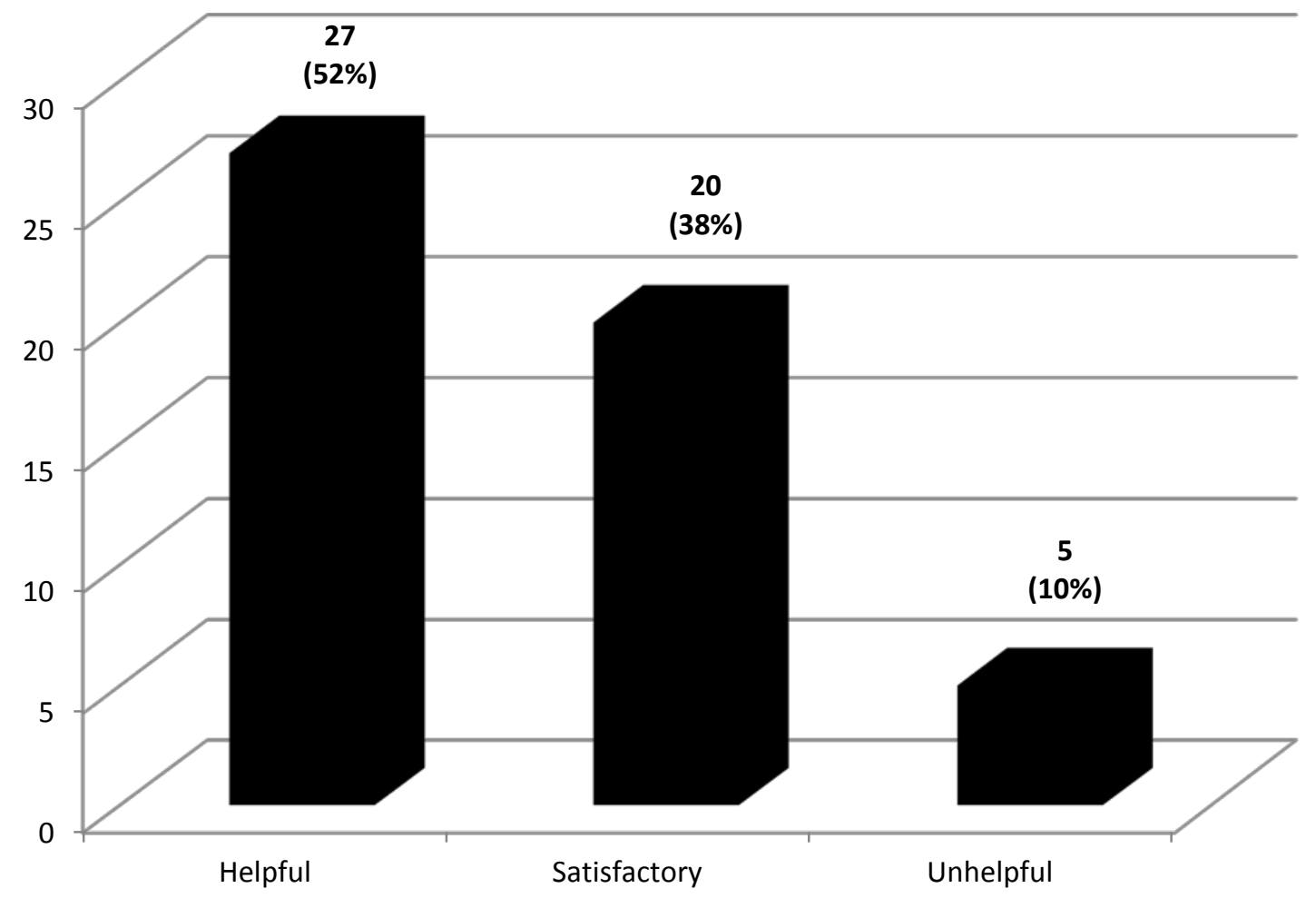


Table 1: Ages of children fostered by kin

\begin{tabular}{|l|l|l|l|}
\hline Age & Number & Percent \\
\hline $0-5$ years & 13 & $15.9 \%$ \\
\hline $6-10$ years & 19 & $23.2 \%$ \\
\hline $11-13$ years & 15 & $18.3 \%$ \\
\hline $14-16$ years & 21 & $25.6 \%$ \\
\hline $17-18$ years & 14 & $17.1 \%$ \\
\hline Total & $\mathbf{8 2}$ & $\mathbf{1 0 0 \%}$ \\
\hline
\end{tabular}

Table 2: Prevalence of disability/illness within age ranges

\begin{tabular}{|l|c|c|c|c|c|c|}
\hline & \multicolumn{2}{|c|}{ Age of kinship foster carer } \\
\cline { 2 - 7 } & $\mathbf{2 2 - 3 0}$ & $\mathbf{3 1 - 4 0}$ & $\mathbf{4 1 - 5 0}$ & $\mathbf{5 1 - 6 0}$ & $\mathbf{6 1 - 7 0}$ & $\mathbf{7 1 +}$ \\
\hline $\begin{array}{l}\text { \% (within age range) who stated they suffer } \\
\text { from a disability which affected their day-to- } \\
\text { day life }\end{array}$ & - & - & - & 4 & 4 & - \\
\hline $\begin{array}{l}\text { \% (within age range) who stated they suffer } \\
\text { from a long-term illness which affected their } \\
\text { day-to-day life }\end{array}$ & - & $\begin{array}{c}1 \\
(22.2 \%)\end{array}$ & $\begin{array}{c}1 \\
(30.8 \%)\end{array}$ & $\begin{array}{c}2 \\
(11.1 \%)\end{array}$ & $\begin{array}{c}(30.8 \%) \\
4\end{array}$ & - \\
\hline Total number of carers in age group & 2 & 8 & 12 & 18 & 13 & 1 \\
\hline
\end{tabular}

Table 3: Age and Self-Described Financial Position

\begin{tabular}{|c|c|c|c|c|c|c|}
\hline \multirow{2}{*}{ Self-described financial position } & \multicolumn{6}{|c|}{ Age of kinship Carer } \\
\hline & $22-30$ & $31-40$ & 41-50 & $51-60$ & $61-70$ & 71+ \\
\hline Comfortable & - & - & $\begin{array}{c}2 \\
(16.7 \%) \\
\end{array}$ & $\begin{array}{c}6 \\
(33.3 \%) \\
\end{array}$ & $\begin{array}{c}4 \\
(30.8 \%) \\
\end{array}$ & $\begin{array}{c}1 \\
(100 \%)\end{array}$ \\
\hline Manageable & $\begin{array}{c}2 \\
(100 \%)\end{array}$ & $\begin{array}{c}6 \\
(75.0 \%) \\
\end{array}$ & $\begin{array}{c}2 \\
(16.7 \%)\end{array}$ & $\begin{array}{c}5 \\
(27.8 \%) \\
\end{array}$ & $\begin{array}{c}6 \\
(46.2 \%) \\
\end{array}$ & - \\
\hline A bit of a struggle at times & - & $\begin{array}{c}1 \\
(12.5 \%)\end{array}$ & $\begin{array}{c}8 \\
(66.7 \%)\end{array}$ & $\begin{array}{c}5 \\
(27.8 \%)\end{array}$ & $\begin{array}{c}2 \\
(15.4 \%)\end{array}$ & - \\
\hline Challenging & - & $\begin{array}{c}1 \\
(12.5 \%) \\
\end{array}$ & - & $\begin{array}{c}2 \\
(11.1 \%) \\
\end{array}$ & $\begin{array}{c}1 \\
(7.7 \%)\end{array}$ & - \\
\hline $\begin{array}{l}\text { Total number of carers in age } \\
\text { group }\end{array}$ & 2 & 8 & 12 & 18 & 13 & 1 \\
\hline
\end{tabular}

